$$
\begin{aligned}
& P J-A B L-238 \\
& 115 \lambda 77110
\end{aligned}
$$

\title{
Poverty, Food Intake, and Malnutrition: Implicažions for Food Security in Developing Countries
}

Maurice Schiff

Alberto Valdés

Reprinted from

American Journal of Agricultural Economics

Vol. 72, No. 5, December 1990

INTERNATIONAL

FOOD

POLICY

- RESEARCH

INSTITUTE

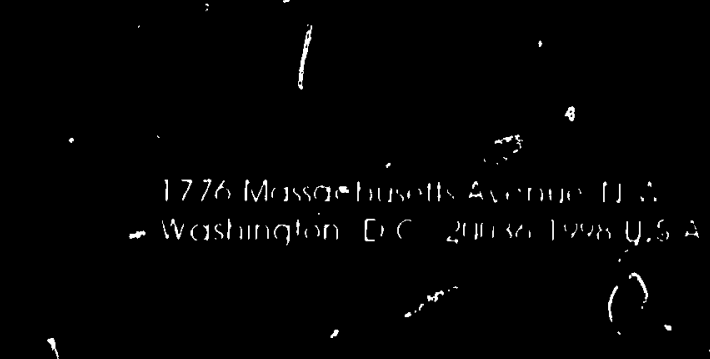

Reprint No. 206 


\section{Poverty, Food Intake, and Malnutrition: Implications for Food Security in Developing Countries}

\section{Maurice Schiff and Alberto Valdés}

The focus of this paper is on the relation between household income, food intake, and nutritional status in less developed countries (LDCs). This article piesent: a framework which relates explicitly houschold behavior patterns with the public policy options designed to improve the nutritional status of the poor in rualal and urban households.

\section{Nutrition and Income: The Statistical Evidence}

Recent literature on the interaction between nutritional status, nutrient intake, and household income has made recommendations on how to improve nutrition based on parameters from empirical studies of food expenditure systems (Behrman and Deolalikar 1988, Alderman, Schiff and Valdés 1990a). However, the policy recommendations derived from the analysis depend critically on the definition of nutrition and, more broadly, on the conceptual framework used. In particular, critical elements of the pathway from changes in income to its effect on nutritional status are still questioned.

It is useful to highlight some fundamental findings on which there is a fair degree of agreement. Estimates from food expenditure systems yield income elasticities of nutrients $\left(\epsilon_{n y}\right)$ somewhat smaller than, but not significantly different from, 1.0. These are derived indirectly by estimating the income elasticities of ford expenditures (also close to 1.0) and by assuming constant nutrient-to-food conversion factors.

More recently, for rural South India, Behrman and Deolalikar (1988) find that the expenditure income elasticity of food for the (6) food

Maurice Schi'f is with the World Bank, and Alberto Valdes is with International Food Policy Research Institute, Washington D.C.

The vic'is expressed in this paper are the sole responsibility of the authors and should not be attributed to the World Bank or to IFPRI. aggregates is close to one. However, for the major riine nutrients, the income elasticities $\left(\epsilon_{n y}\right)$ are not significantly different from zero. As income incres ses, a larger proportion of food expenditures is spent on non-nutrient food attributes such as diversity of products consumed, freshness, taste, convenience foods which save time in their preparation, and others. Similar results are found for low-income households in Pakistan by McCarthy and in several other studius. Based on this evidence Behrman and Deolakikar (1987) conclude that nutrition is unlikely to improve with income. However, if it can be shown that nutrition is not identified exclusively with nutrient intake, then the policy implications might be strikingly different. This is a major objective of this paper.

\section{The Framework}

The starting point is that the nutrition level or status $(N)$ of a household depends only in part on its nutrient intake $(n)$. It also depends on other privately and publicly provided goods and services.'

At the household level, we can think of a process of "producing" nutrition (a nutrition production function), where $N$ is a function of the current as well as lagged values of $(a)$ the nutrient intake (calories, protein, vitamins, etc.) which we call $n,(b)$ the input of non-nutrient food attributes which affact $N$, such as freshness of the foods purchased, their cleanliness, and their storability, which we call $q,(c)$ the privately provided inputs which may affect $N$, such as the time and care to prepare food including cleaning, cooking, boiling water, and other inputs (refrigeration) that ensure that the food does

\footnotetext{
'A formal development of this framework is found in Schiff and Valdés (1990a).
} 
not become contaminated or spoiled, which we call $p,(d)$ the publicly provided inputs which would include potable water, sewerage, electricity, nutritional information, etc., which we call $k$. The production of $N$ is also partly determined by the individuals' health status, age, sex, and location (rural or urban). A fall in health resulting from causes other than a fall in $n, q$, $p$, or $k$ above-say, because of a reduction in medical services-will result in a fall in $N$.

Only in the extreme case of famine (i.e., as nutrient intake approaches zero), would all food expenditures be allocated to nutrients $n$, the impact on $N$ of the other variables, particularly $q$, would tend to zero and only an increase in nutrients would have a significant impact on $N$. In that case, $\epsilon_{n y}$ would be close to one. However, the vast majority of the population in developing countries does not fall under this extreme case of famine.

In a broader sense, the variable of concern is household's welfare, an important component of which is the health status $(H)$ of its members, which depends in part on their nutritional status. As with nutrition, at the household level we can think of a health production function, $H$, which is a function of $(a)$ nutritional status referred to above, $(b)$ privately provided inputs $(p),(c)$ publicly provided inputs $(k)$, and $(d)$ a variable $(m)$ of current and lagged values of additional inputs affecting health. In fac!, the variable $m$ consists of both privately provided inputs (amount and quality of child care, hygiene, etc.), and of publicly provided inputs (medical services, information on hygiene and child care, and other). Finally, the production of health is also a function of age, sex, and location (rural or urban) of the individual. Thus, health depends on privately and publicly provided inputs directly, as well as indirectly through their effect on nutrition.

Because the functions $N$ and $H$ may vary according to sex, age, location, and other individual characteristics, the impact on $N$ and $H$ of changes in each determinant $n, q, p, k$, and $m$ also may vary according to those characteristics.

Tinis framework allows us to further elucidate the question of whether income gains in lowincome communities could reduce malnutrition (raise $N$ ), even when they have only a very marginal effect on nutrient intake at the household level. How these two variables, $N$ and $H$, respond when income gains occur among low-income households is then the central concern in this paper.

From the production function of nutrition $(N)$ defined above, we can derive the income elasticity of nutrition (See appendix for details.):

$$
\epsilon_{N y} \equiv A+\epsilon_{N H} \epsilon_{H y},
$$

where $N$ is level of nutrition, $H$ is level of health, $y$ is the household's income, $\epsilon$ is the income elasticity, and $A$ is the partial elasticity of $N$ with respect to income (for a given health status) and incluses the impact of income on $n, k, q$, and p.

Similarly with health status, given the production function of health described above, we derive the income elasticities, namely

$$
\epsilon_{l y} \equiv \epsilon_{H N} \epsilon_{N y}+B,
$$

where $B$ is the partial income elasticity of $H$ (for a given $N$ ). Variable $B$ includes the income elasticities of privately provided inputs $\epsilon_{p y}$ of publicly provided inputs $\epsilon_{k y}$ and of the other variable $\epsilon_{m y}$ affecting health (such as medical services, information on hygiene and child care, and others). Solving for $\epsilon_{N y}$ and $\epsilon_{H y}$, we obtain

$$
\begin{aligned}
\epsilon_{i y} & =\frac{A+B \epsilon_{N H}}{1-\epsilon_{N H} \epsilon_{H N}}, \text { and } \\
\epsilon_{H y} & =\frac{B+\epsilon_{H N} A}{1-\epsilon_{N H} \epsilon_{H N}} .
\end{aligned}
$$

We postulate that $\epsilon_{q y}, \epsilon_{p y}, \epsilon_{k y}, \epsilon_{m y}>0$; that is, increases in household's income will be acconipanied by an increase in the demand for food "quality" - e.g., freshness, cleanliness, level of processing, and taste of purchased foods $(q)$ in the care in preparing food, and in the use of household appliances such as refrigerators $(p)$, and in more income spent on potable water, electricity, and sewerage systems $(k)$. Also, richer households will use more medical and other health-related services, and may provide healthrelated child care $(m)$. The positive income elasticities for $q, p, k$, and $m$ imply that $A>0$ and $B>0$, which in turn implies that $\epsilon_{N y}>0$ and $\epsilon_{H y}>0$. Consequently, the impact of income on $N$ may be significant, even though nutrient intake remains unchanged or increases only slightly with income.

What we are trying to emphasize here is that to assess the impact of income on nutrition, one should not simply examine the impact on the input $n$ but should look at the entire production function $N$. Furthermore, if the ultimate concern is with improving the health status $H$ ( $N$ being one input in the production of $H$ ), then again the impact of income on health status $H$ may be quite important. The fact that the nutrient in- 
come elasticity is close to zero $\left(\epsilon_{n y}=0\right)$ and the food expenditure elasticities are close to i.0 $\left(\epsilon_{F y}\right.$ $=1$ ) implies that the demand for non-nutrient food attributes (variety, storability, cleanliness) is high at those low income levels $\left(\epsilon_{q y}>1\right)$.

This framework is consistent with the finding, for example by Shah in rural India, and more recently Behrman and Deolalikar (1987), that even at such a low level of family income, as income increases, household's demand a wider variety of food products with a larger quantity of non-nutritive attributes (freshness, taste, processing, etc.). At the same time, however, the actual increase in nutrient intake associated with increases in the household's income is not significantly different from zero. Thus, families have a choice of spending increments in food expenditures on nutrients $n$ but choose to spend their additional income on non-nutrient food attributes $(q)$. And this choice, depending on which element of $q$ is selected (say, freshness rather than taste), might even lead to an increase in nutrition or health.

Thus, the common practice of estimating the number of hungry and undernourished by comparing calorie and other nutrient intake with requirement standards implies that, in addition to ignoring the impact of intputs of non-nutrient attributes $(q)$ and privately provided inputs $(p)$ on nutrition, no weight is given to household preference. No matter how closely related, food adequacy (measured by nutrient intake) and nutrition level are not the same thing. The problem of food adequacy may or may not reveal itself as a nutrition problem; and a nutrition problem may or may not be the result of an inadequate supply of food. ${ }^{2}$

\section{Policy Implications}

Considering that the policy objective is to raise the level of nutrition or health, the approach developed above suggests that, except in the case of famines, a variety of alternative policy instruments is available and their relative merits may change according to location (rural or urban), initial conditions of infrastructure, etc. It also suggests that income will affect nutrition (and health) through its impact on $q, p$, and $H$

\footnotetext{
${ }^{2}$ Of course, in the extreme case of famine, malnutrition is the result of inadequate food supply.
}

(and $m$ ), even if it has little or no impact on nutrient intake $n .^{3}$

Education undoubtedly plays an important role; one might expect the nutrition and health-related child care to improve with the level of the mother's education. In his study for India, Padmanabha finds that infant mortality falls both in rural and urban areas as the literacy and formal educational level of the mother increases. The eviderce may not be entirely conclusive, as income may be positively correlated with the mother's education and was not controlled. Garcia and Pinstrup-Andersen, in their study on the Philippines, find that the mother's education strongly affects the food consumption and nutritional status of preschoolers.

If the concern is with the production of health, and taking infant mortality as one indicator of health, Padmanabha argues that in rural areas in India, the main causes of death are tetanus, pneumonia, dysentery, and typhoid. These diseases are mainly conditioned by the absence or availability of basic facilities such as reliable water supply, sanitation $(k)$, and basic child care services $(m)$, so that nutrient intake does not seem to be the major factor. This confirms the results obtained by Castañeda for Chile, where the most important variable explaining the remarkable reduction of infant mortality in Chile from 107 per 1,000 in 1965 to 19.4 per 1,000 in 1986 was the increase in urban coverage of potable water and sewerage. Differences in such coverage were statistically more important than the positive impact of the available nutritional programs addressed to mothers. Thus, governments may have to increase the level and quality of publicly provided inputs ( $k$ and $m$ above) in order to have a lasting impact on nutrition and health.

Providing information and education on hygiene and child care may also be effective ways of raising nutrition and health. Direct demonstration in the rural areas, like in the Iringa Integrated Nutrition Program in Tanzania, or provision of information via television, which has been very successful in raising privately pro-

\footnotetext{
${ }^{3}$ If, alternatively, nutritional status is measured as $(n)$, then $N$ is not responsive to $y$, given that nutrient consumption has been found to be rather unresponsive to changes in income. Thus, transfer programs will be ineffective means to improve nutrition. Similarly, as argued by Alderman. a weak link between income and nutrition implies that nutrition is to some degree buffered from the downswings in the local economy. Under such scenario, and given that definit. on of $N$, for income to have an impact on nutrition, policies must be designed to raise the income elasticity of nutrient intake $\left(\epsilon_{n y}\right)$; some analysts have argued that raising the mother's education could be another way to do it.
} 
vided inputs $(p)$ and $(m)$ in Chile, are logical approaches to exploit the complementarities in the production of health and nutrition. Here, we refer to the private component of $m$, but, as mentioned earlier, there is also a public component of $m$. Also, policies designed to raise the nutrient content of some food ingredients, such as food fortification programs, lead to an increase in the level of nutrition by raising $n$.

Concepiually, the framework presented above can help in the evaluation of public investment programs to raise health and nutrition for the poorer households. However, in order to devise effective policies to raise $H$ and $N$, research efforts should be directed at the empirical estimation of $(a)$ the technological production functions of $N$ and $H$, to know the impact of $p, q$, $k$, and $m$ on $N$ and $H$; and (b) the behavioral relationships to estimate $\epsilon_{p y}, \epsilon_{q y}, \epsilon_{k y}$, and $\epsilon_{m y}$, so as to compare the effectiveness of raising $N$ and $H$ through $y$, and through $k$ and $m$ (public components)- or a combination of both; and (c) the costs of providing the services, so as to identify and select cheaper and more efficient programs designed to raise the nutritional and health status of the poorer households.

One would expect that the parameters of these functions $N$ and $H$ differ according to age, sex, income class, and rural and urban characteristics. The estimation of these parameters should be part of the research agenda.

\section{The Distinction between Urban and Rural Populations}

The distinction between urban and rural households could raise a particularly complex issue. For governments to provide medical services and drinking water and sewers in urban areas is probably considerably less expensive than to provide it for rural areas. Given the lower population density in the latter, the cost per household scattered over large areas would be considerably higher. On the benefits side, they are probably lower in rural areas, considering that the lower population densities in rural areas would reduce the need for publicly provided sewers, drinking water and other such service.

Thus, if the low levels of $N$ and $H$ are the social concem, raising those levels in urban areas by increasing expenditures on $k$ and on public components of $m$ may be an efficient public policy. However, this may very well not be the case for rural areas because of higher costs and lower benefits of providing $k$ and the public compr:nents of $m$.

What then is the prescription for rural areas? One important implication is that nutritional and health status in rural areas will then largely depend on the levels of inputs $(p, q$, and the private components of $m$ ), which are provided by the households. These levels depend on income, so that raising rural household's income can raise their nutritional and health status. For example, it may be easier to make a significant impact on incomes in a rural community through a variety of agricultural programs and policies than it is to appreciably increase the provision of sewerage or of health care delivery.

We are back then to the long-debated question on how to best raise farm income. One way would be to reduce the taxation of agricultural production caused by sector-specific and economy-wide policies in LDCs. ${ }^{4}$ Another would be to increase public expenditure in those factors which raise land and labor productivity. In principle both are necessary and the right balance between them is an empirical question to be addressed on a country-by-country basis.

\section{Concluding Comments}

While food is continuously referred to in this paper, little is said about agriculture. There is, however, a strong link with agriculture because, as the analysis suggests, in rural areas the nutritional and health status will largely depend on the levels of private inputs ( $p, q$, and the private components of $m$ ), which are provided by the households. These levels depend on income, so that raising rural income can raise their nutritional and health status.

The evidence suggests that the development strategies since World War II in most developing countries grossly undervalued the potential contribution of agriculture to economic development. Preliminary estimates for eighteen LDCs show that in most of these eighteen countries, the agricultural sector lost approximately one-fourth of agricultural GDP during 1960-84, as a result of the sectoral and economy-wide price interventions (Schiff and Valdés 1990b). The cumulative effect over time of such a transfer of income out of agriculture must have had a significant repercussion in aggravating poverty in

\footnotetext{
4 An analysis of the impact of those policies for 18 developing countries during 1960-84 is provided in Krueger, Schiff, and Valdes.
} 
rural areas. According to the conceptual link between income, nutrition, and health developed earlier, this evidence on income transfers suggests that these domestic economic policies probably had very detrimental effects on nutrition and health status of the poorest segments of the population. Policy reform in the developing countries should make an important contribution in alleviating rural poverty in developing countries.

\section{References}

Alderman, H. "Poverty and Malnutrition: How Closely Linked?" Cuadernos de Economia, August 1989.

Bchrman, J. R., and A. B. Deolalikar. "Health and Nutrition." Handbook of Development Economics, vol. 1, ed. H. Chenery, and T. N. Srinivasan. Amsterdam: North-Holland Publishing Co., 1988.

—. "Will Developing Country Nutrition Improve with Income?: A Case Study for Rural South India." J. Polit. Econ. 95(1987):452-507.

Castan̄eda, T. Innovative Social Policies for Reducing Poverty: Chile in the 1980s. Baltimore MD: Johns Hopkins University Press for the World Bank, forthcoming.

Garcia, M., and P. Pinstrup-Andersen, The Pilot Food Price Subsidy Scheme in the Philippines: Its Impact on Income, Food Consumption, and Nutritional Status. Washington DC: IFPRI Res. Rep. No. 61, Aug. 1987.

Krueger, A. O., M. Schiff, and A. Valdés. "Agricultural Incentives in Developing Countries: Measuring the Effects of Sectoral and Economy-wide Policies." World Bank Econ. Rev. 2(1988):255-71.

McCarthy, D. "Food Consumption, Income Distribution and Quality Effects." Food Pol. 2(1977):79-82.

Padmanabha, P. "Mortality in India: A Note on Trends and Implications. " Econ. and Polit. Weekly 17(1982):128590.

Schiff, M., and A. Valdés. "Nutrition: Alternative Definitions and Policy Implications." Econ. Develop. and Cultur. Change 38(1990a):281-92.

- The Economics of Agricultural Price Interventions in Developing Countries, vol. 4. Baltimore MD: Johns Hopkins University Press, 1990b.

Shah, C. H. "Food Preference, Poverty, and the Nutrition Gap." Econ. Develop. and Cultur. Change 31(1983): $121-48$.

\section{Appendix}

\section{Derivations}

We propose the following alternative definition for the nutrition production function:
(1)

$$
\begin{aligned}
N=N(n, q, p, k, H ; S, E, L), \\
\epsilon_{N n}, \epsilon_{N q}, \epsilon_{N p}, \epsilon_{N h}, \epsilon_{N H}>0,
\end{aligned}
$$

where $n$ is a vector of inputs of nutrients, $q$ is a vector of inputs of non-nutrient food attributes, $p$ is a vector of other privately provided inputs, $k$ is a vector of publicly provided inputs, $H$ is health status, $S$ is sex, $E$ is age, $L$ is urban or rural location, and where $n, q, p$, and $k$ are lag polynomials in those variables, reflecting the effect of current as well as lagged values of those variables.

A health production function can be defined as

$$
H=H(N, p, k, m ; S, E, L), \quad \epsilon_{H N}, \epsilon_{H p}, \epsilon_{H k}, \epsilon_{H m}>0,
$$

where $\boldsymbol{m}$ is the vector of current and lagged values of additional inputs affecting health, such as medical services, inturmation on hygiene and child care, and other. Health deperids on $p$ and $k$ directly, as well as indirectly through their eifect on $N$.

Because $\boldsymbol{N}$ and $\boldsymbol{H}$ depend positively on current as well as lagged values of their arguments, the long-run elasticities will tend to be larger than the short-run elasticities. Also, the functions $N$ and $H$ may vary according to sex, age, location, and other individual characteristics, so that the elasticities of $N$ and $H$ with respect to their arguments may also vary according to those characteristics.

Finally, in terms of income elasticities:

$$
\begin{aligned}
\epsilon_{N y}=\epsilon_{N h}^{\prime} \epsilon_{n y}+\epsilon_{N q}^{\prime} \epsilon_{q y} & +\epsilon_{N p}^{\prime} \epsilon_{p y} \\
& +\epsilon_{N k}^{\prime} \epsilon_{k y}+\epsilon_{N H} \epsilon_{H y} \equiv A+\epsilon_{N H} \epsilon_{H y},
\end{aligned}
$$

and from equation (2) the income elasticity of health status is

$$
\epsilon_{H y}=\epsilon_{H N} \epsilon_{N y}+\epsilon_{H p}^{\prime} \epsilon_{p y}+\epsilon_{H h}^{\prime} \epsilon_{k y}+\epsilon_{H m}^{\prime} \epsilon_{m y}=\epsilon_{H N} \epsilon_{N y}+B,
$$

where $\epsilon^{\prime}$ is a row vector. Solving for $\epsilon_{N Y}$ and $\epsilon_{H Y}$ from equations (3) and (4), we obtain

$$
\begin{aligned}
& \epsilon_{N y}=\frac{A+\epsilon_{N H} B}{1-\epsilon_{N H} \epsilon_{H N}}, \text { and } \\
& \epsilon_{H y}=\frac{B+\epsilon_{H N} A}{1-\epsilon_{N H} \epsilon_{H N}} .
\end{aligned}
$$

We postulate that $\epsilon_{q y}, \epsilon_{p y}, \epsilon_{k y}, \epsilon_{m y}>0$; that is, an increase in household's income will tend to be accompanied by an increase in the demand for food "quality, " e.g., freshness, cleanliness, and taste of purchased foods $(q)$, in the care in preparing food, and in the use of household appliancts such as refrigerators $(p)$, and in more income spent on $1 . .$. hie water, electricity, sewerage systems, etc., $(k)$. Also r.:. households will use more medical and other health-relal $d$ services and may provide health-related child care $(m)$. Thus, $A>0$ and $B>0$. Since, for stability, $1-\epsilon_{N H} \epsilon_{H N}>0$, this implies that,

$$
\epsilon_{N y}>0 \text { and } \epsilon_{H y}>0 .
$$

